\title{
Uso do Sistema de Avaliação da CAPES por Programas de Pós-Graduação em Administração no Brasil
}

\author{
Emerson Antonio Maccari ${ }^{1}$ \\ Manolita Correia Lima ${ }^{2}$ \\ Edson Luiz Riccio ${ }^{3}$
}

\section{Resumo}

O sistema brasileiro de avaliação de programas de pós-graduação vem evoluindo desde 1976, e é considerado um dos mais modernos do mundo. Esse sistema tem se revelado o principal direcionador do desenvolvimento da pós-graduação no país. Nesse contexto, deseja-se investigar: como o sistema de avaliação adotado pela CAPES vem sendo utilizado pelos programas de pós-graduação stricto sensu em Administração no Brasil? E de que modo ele tem colaborado para o fortalecimento de tais programas? Para tanto, realizou-se uma pesquisa orientada pelo método de estudo de casos múltiplos que permitiu o aprofundamento dessas questões em quatro unidades de estudo (programas de pós-graduação) públicos e privados, em diferentes estágios de desenvolvimento. Como resultado, verificouse que: 1) o sistema de avaliação tem grande influência no desenvolvimento dos programas e é o seu principal direcionador estratégico; 2) os critérios e itens de avaliação estão bem definidos e são conhecidos pela comunidade acadêmica avaliada; 3) o sistema demanda alta qualidade e produtividade e encoraja os programas a ampliarem sua inserção na comunidade.

Palavras-chave: Avaliação. Avaliação da Pós-Graduação. Sistema de avaliação da Pós-Graduação. Sistema de Avaliação da CAPES.

\footnotetext{
${ }^{1}$ Doutor em Administração pelo Programa de Pós-Graduação em Administração - PPGA/FEA USP. Professor do Programa de Mestrado e Doutorado em Administração - PMDA. Universidade Nove de Julio - UNINOVE. Endereço: Av. Francisco Matarazzo, 612 Água Branca, CEP 05001-100 - São Paulo-SP - Brasil. E-mail: emersonmaccari@gmail.com.

${ }^{2}$ Doutora em Educação pela Universidade de São Paulo. Professora do Núcleo de Estudos em Gestão Internacional - NEGI. Escola Superior de Propaganda e Marketing - ESPM. Escola Superior de Propaganda e Marketing. Endereço: Rua Doutor Álvaro Alvim nº. 123 Vila Mariana. CEP 04018-010 - São Paulo - SP - Brasil.E-mail: mclima@espm.br.

${ }^{3}$ Pós-Doutor pela Universite de Toulon Et Du Var, U.TOU.V*, França. Professor do Programa de Pós-Graduação em Controladoria e Contabilidade. Universidade de São Paulo - USP. Endereço: Av. Prof.. Luciano Gualberto, 908 FEA 3, Cidade Universitária, CEP 05508900 -São Paulo-SP-Brasil. E-mail: elriccio@usp.br. Artigo recebido em: 10/04/2009. Aceito em: 21/11/2009. Membro do Corpo Editorial Científico responsável pelo processo editorial: Rolando Juan Soliz Strada.
} 


\section{Introdução}

Nas últimas décadas, o monitoramento do desempenho, por meio de sistemas de avaliação, tornou-se um mecanismo estratégico para as nações que apostam no domínio tecnológico como meio de ampliar suas reservas econômicas e obter acesso a bens e serviços. Dessa forma, o desempenho cognitivo passou a ser fator de competitividade para organizações e países, valorizando o conhecimento e, por consequência, conferindo cada vez mais importância à avaliação da educação superior.

Porém, a avaliação como controle é uma questão demasiadamente estática e fechada, recorrentemente associada à ideia de castigo, utilizada para vigiar e punir (FOUCAULT, 1983). Para torná-la eficiente é indispensável que sua função (antes restrita ao controle) se transforme em um processo e por isso mesmo evolua da coleta, seleção e tratamento de dados e informações, para a interpretação e conversão em conhecimento passível de ser disseminado, contribuindo de forma dinâmica, aberta e construtiva para a tomada de decisões (UNESCO, 1998).

Nesta direção, pensar a avaliação equivale a formular diagnósticos confiáveis e conceber melhorias orientadas para o aprimoramento das Instituições de Educação Superior (IES). Por isso, em tempo algum a centralidade do debate acerca da qualidade da educação ganhou tanto espaço. É nesse contexto que a avaliação do ensino (estudantes, professores, ensino e aprendizagem), cursos, programas, instituições e sistemas educacionais ganham notabilidade no ambiente acadêmico, e envolve igualmente a sociedade, o Estado $e$ as agências internacionais multilaterais (UNESCO, OCDE, entre outras) uma vez que as transformações contemporâneas exigem transformações no interior das IES, em espaços de tempo cada vez menores.

Ao destacarem a nova dinâmica do processo avaliativo Schwartzman (1990) e Durham (1992) asseguram que a prática da avaliação ganha forças na medida em que podem colaborar para a solução de duas questões. Uma refere-se ao papel do Estado cuja função é orientar os financiamentos e canalizar as pressões que recebe da sociedade no sentido de ampliar o acesso ao ensino de qualidade, com estreita relação com o setor produtivo. E a outra diz respeito às próprias universidades, visando evitar um duplo perigo: o primeiro, diz respeito à incapacidade de responder às pressões da sociedade $e$ de se tornarem instituições obsoletas sem condições de atrair os financiamentos de que necessitam; o segundo refere-se à capacidade de as universi- 
dades lidarem com pressões imediatistas e prejudiciais à capacidade de desenvolver pesquisa científica básica, estudo de humanas e, ao mesmo tempo, garantir a autonomia da investigação, fundamental para preservar o papel crítico e inovador da instituição.

A literatura consultada assegura que as IES não conseguem responder adequadamente às crescentes e diversificadas demandas ou modificar suas tradicionais estruturas e modos de funcionamento, sem prévio processo de avaliação. Nesse sentido, para tomar decisões e direcionar esforços para a mudança é indispensável conhecer a situação corrente, as capacidades existentes e as que devem ser construídas (RODRIGUES, 2003). Nesta direção, a avaliação não é um modismo, tampouco uma simples imposição do Estado, afinal o processo avaliativo pode impedir que se disseminem os vícios de um planejamento burocrático rígido, característico de países de ensino público centralizado, que tem se revelado ineficiente e ineficaz para atender às necessidades de transformação cuja exigência fundamental é a flexibilidade (DURHAM, 1992). Sendo assim, a definição de desempenho e o desenvolvimento de sistemas de avaliação passam a ser prioridades para os países que desejam alcançar padrões de qualidade mundialmente aceitáveis (ELKHAWAS, 1998).

Allen (1996) destaca a importância da relação existente entre o resultado e a qualidade do sistema de avaliação como um todo. Gatti (2006), por sua vez, argumenta a necessidade de desenvolver sistemas de avaliação que contenham materiais quantitativos e qualitativos cujos resultados permitam a formulação de indicadores de qualidade da educação, levando-se em conta as diferenças existentes nas diversas áreas avaliadas. A autora adverte que uma das formas de ampliar o impacto positivo da avaliação sobre o programa e a instituição consiste em envolver os participantes no processo avaliativo. Dessa forma, legitimam-se processos e resultados, além de criarem condições que favorecem a aprendizagem dos participantes - aspecto preponderante - uma vez que conhecer os paradigmas da avaliação, o programa e a instituição possibilita o autodesenvolvimento e amplia a capacidade de compreender e de intervir sobre o ambiente educacional.

Gaetani e Schwartzman (1993) fazem uma defesa explícita dos méritos da avaliação quantitativa. Para os autores, na avaliação quantitativa existe a preocupação de trabalhar com o suporte de um método que reflita as características da comunidade ou da área envolvida, bem como a preocupação com a quantificação das variáveis decorrentes da necessidade de se obter 
um modelo passível de reprodução em qualquer programa, ano após ano, tratando-se de um modelo generalizável. No entanto, advertem que dependendo da área, os fatores críticos para a realização de uma avaliação devem variar ou considerar pesos diferentes.

Destacam, ainda, que a avaliação qualitativa apresenta um grau de complexidade maior na medida em que gera dificuldade de se estabelecer critérios e procedimentos capazes de trabalhar a questão da qualidade de forma operacional. Além disso, o uso desse tipo de abordagem amplia as chances de ocorrer divergências entre os participantes devido ao elevado grau de subjetividade e isso dificulta a sua tradução em resultados e ações corretivas.

De toda forma, a medida da qualidade de um sistema de avaliação é obtida por meio da introdução de parâmetros para avaliar as atividades desenvolvidas pelas instituições avaliadas. Em geral, as medidas de qualidade, sejam elas definidas por agências governamentais, agências privadas ou independentes, tendem a instaurar mecanismos que cobrem conformidade a determinados padrões, por meio dos processos de supervisão, especialmente pela prática da avaliação por pares (peer review) (INEP, 2006).

Dada à importância da avaliação no que concerne à definição das diretrizes para o desenvolvimento da educação, é relevante estudar a contribuição do sistema de avaliação em vigor para melhoria da gestão dos programas brasileiros de pós-graduação, pois, ao que parece, o potencial dessa ferramenta de gestão ainda não é adequadamente explorado. Nesse sentido, o objetivo deste artigo reside em responder às seguintes dúvidas: como o sistema de avaliação adotado pela CAPES vem sendo utilizado pelos programas de pós-graduação stricto sensu em Administração, no Brasil? De que modo ele tem colaborado para o fortalecimento de tais programas?

\section{A Avaliação em Discussão}

A implantação de sistemas de avaliação não é um fenômeno exclusivamente brasileiro, ela surgiu e se fortaleceu de diferentes formas (metodologias) e com graus variados de abrangência em diversos países (DURHAM, 1992). Apesar de ter uma tradição mais antiga na América do Norte, a temática da avaliação do ensino superior permanece pouco desenvolvida no contexto latino americano e europeu (SCHWARTZMAN, 1990). 
Afonso (2000) afirma que, desde o começo dos anos de 1990, principalmente nos países anglo-saxônicos, as funções mais importantes da avaliação estavam relacionadas à gestão produtivista do sistema educativo. Nesses países, de acordo com Willis (1992), a avaliação funcionava como instrumento auxiliar nas escolhas dos consumidores da educação e, por consequência, na criação e ampliação de um mercado educacional.

Rapidamente, a relação entre o processo avaliativo e a definição das políticas educacionais dos países é explorada. Por isso, House (1992); Allen (1996) e Durhan $(1992,2006)$ asseguram que a avaliação no âmbito educacional é afetada por interesses e forças políticas, uma vez que está a serviço de políticos e legisladores dispostos a diagnosticar e resolver problemas da política educacional por meio da avaliação. Razão pela qual, durante muito tempo, o objetivo da avaliação se concentrou em diagnosticar as deficiências dos sistemas educacionais e denunciar a necessidade de transformações substanciais. Na mesma direção, Linn (1995, apud ALLEN, 1996) reforça que, mesmo em períodos mais recentes, a avaliação tem sido utilizada como um meio de promover e legitimar reformas educacionais.

A necessidade de avaliação por parte do Estado é mais visível em momentos de incertezas ou dúvidas sobre a recepção ou a consecução de determinadas políticas públicas. Quando isso ocorre, o Estado solicita a realização de avaliações para reforçar a credibilidade de sua ação, (MULLER apud AFONSO, 2000; DURHAN, 1992). Porém, House (1992); Allen (1996) e Durham (1992; 2006) advertem que a avaliação da educação não pode ser utilizada como instrumento de centralização e pressão unilateral do Estado e tampouco como um elemento capaz de substituir as pressões de mercado por uma publicização (como no caso dos EUA) que provoque pressões generalizadas no sentido de promover a adaptação das instituições de ensino.

É fato que, as pressões advindas da avaliação podem gerar mudanças nos comportamentos organizacionais e na gestão das IES, haja vista que elas introduzem regras externas que se vão articulando aos sistemas internos, podendo ou não alterar a arquitetura institucional (INEP, 2006). No limite, a avaliação tem possibilitado que as IES se conheçam melhor, repensem $e$ redesenhem seus processos. Como resultado, percebe-se que as instituições estão cada vez mais parecidas umas com as outras. Isso é consequência do isomorfismo coercitivo resultante de pressões exercidas por uma organização (o sistema de avaliação) sobre a outra que dela depende (a universidade ou o programa). $\mathrm{O}$ isomorfismo pode ser caracterizado como um fenômeno que 
atua como um conjunto limitador, o qual obriga uma organização a parecer com outras que enfrentam as mesmas condições ambientais (DI MAGGIO; POWELL, 1991). Essa convergência ocorre tanto por pressões formais quanto informais. Alemán (2005) reforça essa constatação ao afirmar que instituições com missões, objetivos, estratégias e naturezas (pública e privada) diferentes respondem de maneira similar a um mesmo processo de avaliação externa.

\section{Sistema de Avaliação da Pós-Graduação no Brasil}

Desde que agências oficiais de apoio à pesquisa foram criadas, as atividades de pesquisa, desenvolvidas pelas universidades, e seus respectivos resultados são alvos de avaliações constantes. As primeiras experiências envolvendo uma avaliação mais ampla das universidades brasileiras datam de 1976/77, com a criação de Programas de Avaliação de Cursos de Pós-graduação, concebidos e implantados pela Fundação Coordenação de Aperfeiçoamento de Pessoal de Nível Superior (CAPES), órgão vinculado ao Ministério da Educação. Os objetivos inicialmente declarados para justificar a concepção e adoção de programas de avaliação dos cursos de pós-graduação podem ser resumidos nos seguintes termos: (a) facilitar a distribuição de bolsas de estudo para mestrandos e doutorandos e orientar o investimento das agências federais na formação de recursos humanos de alto nível; (b) subsidiar a política educacional relativa à pós-graduação e à universidade, assim como suas relações com a educação básica; (c) além de criar um sistema permanente de informações sobre a pós-graduação brasileira. De acordo com o INFOCAPES (1996) pelo menos dois outros objetivos devem ser somados àqueles oficialmente declarados: (a) regular a expansão da pós-graduação, recomendando o apoio aos cursos novos e incorporando-os progressivamente ao sistema de avaliação e acompanhamento; e (b) credenciar esses cursos, tornando válidos, em plano nacional, os certificados por eles expedidos.

Desde o início da implantação do programa de avaliação da pós-graduação houve a decisão de que a sua sistemática se orientaria pelos produtos alcançados, o que permitiria efetuar-se o processamento dos dados coletados, utilizando-se de procedimentos quantificáveis. Sendo assim, anualmente, relatórios detalhados sobre os programas e cursos avaliados eram elaborados, e os dados reunidos eram processados pela CAPES e analisa- 
dos pelos membros das comissões de especialistas formadas para este fim. Em 1980, com a preocupação de aprofundar a análise dos dados disponibilizados anualmente pelos programas avaliados, a sistemática foi aperfeiçoada na medida em que foram incorporadas visitas in loco, realizadas a cada dois anos por consultores ad hoc, designados pela CAPES (GATTI, 2000).

Em meados de 1990, com a informatização dos sistemas da CAPES, ocorreu expressivo aprimoramento do processo de avaliação. Adicionalmente, houve uma melhor divisão das áreas do conhecimento, além da adoção de critérios mais rígidos para atribuição de notas aos cursos. Em grande parte isso se deveu aos resultados da avaliação de 1994: 41\% dos cursos de mestrado e $53 \%$ dos de doutorado obtiveram conceito A - naquela oportunidade, correspondia à maior nota na escala em vigor (INFOCAPES, 1996). Os resultados da avaliação realizada em 1996 foram ainda mais preocupantes: $79 \%$ dos cursos de mestrados e $90 \%$ dos de doutorado obtiveram conceito A ou $\mathrm{B}$ revelando que o sistema de avaliação passou a emitir nítidos sinais de esgotamento, ao não conseguir discriminar mais a qualidade acadêmica entre os cursos avaliados (NICOLATO, 2000).

Esse autor destaca que, após discussões realizadas no âmbito do Conselho Técnico-Científico (CTC) e do Conselho Superior da CAPES, foram introduzidas modificações, tanto nos critérios quanto na atribuição de notas para apreciação dos cursos. Além disso, decidiu-se que a avaliação passaria a ser trienal, com o acompanhamento anual de desempenho dos cursos. Outra importante mudança foi a vinculação dos resultados da avaliação à homologação do CTC.

O processo de modernização do programa de avaliação da fundação merece especial destaque no que tange a dois aspectos reconhecidos como problemáticos: o comprometimento da capacidade discricionária da classificação adotada (a), e o efeito homogeneizador da avaliação, decorrente da pressão exercida pelos critérios (padrões de qualidade) adotados, sobre os programas avaliados (b). Fator que, por um lado inibe a construção de uma identidade própria a cada curso e, por outro, estimula à incorporação de um padrão comum imposto pela avaliação na medida em que este se torna necessário e suficiente para a recomendação, o credenciamento e a obtenção do apoio governamental.

Alguns acadêmicos chamaram atenção para os riscos de se adotar um único padrão de qualidade para múltiplos programas de pós-graduação quan- 
do tais programas estão orientados por diferentes contextos históricos, geográficos, materiais, institucionais, acadêmicos e pedagógicos. É possível que essa prática iniba o potencial inovador dos supracitados programas e favoreça os pequenos e recentes devido à agilidade que apresentam de inovar tanto em termos curriculares quanto em termos regimentais. Nesse contexto, os programas tradicionais, oferecidos por universidades consolidadas, podem ser penalizados.

Tudo isso contribuiu para que em 1998, a CAPES imprimisse significativas alterações à sistemática de avaliação. Qual a direção assumida por essas alterações? Até então, os programas avaliados eram classificados em conceitos que variavam entre $\mathrm{A}, \mathrm{B}, \mathrm{C}, \mathrm{D}$ e $\mathrm{E}$, entretanto, o comprometimento da capacidade discricionária de classificação dos procedimentos, antes mencionada, levou a Fundação a estabelecer sete níveis de conceitos, de modo que as classificações superiores a cinco ficaram imitadas aos programas que ofereciam cursos de doutorado e as classificações superiores a seis ficaram limitadas aos programas de nível internacional (CAPES, 2002).

Outra novidade é que a avaliação passa a considerar o programa e não mais o curso, como tinha ocorrido até então. Apesar dos protestos, concentrados particularmente entre os programas que - diante da nova sistemática - foram rebaixados, a seriedade do trabalho realizado pela CAPES tem sido reconhecida internacionalmente e sua sistemática de avaliação é uma referência na área, tanto em razão da eficiência conquistada - mais de 2.700 programas avaliados (CAPES, 2009) - quanto pela eficácia, exigência de qualidade na produção intelectual e formação discente. Indiscutivelmente, isso tem contribuído para o reconhecimento nacional e internacional da qualidade acadêmica dos programas de pós-graduação oferecidos pelas instituições educacionais brasileiras.

Para Gassola (apud SBPC, 2008), não há na América Latina e no Caribe, e é até difícil encontrar no restante do mundo, um sistema de avaliação comparável ao adotado no Brasil. Para o autor, quando se compara o sistema de pós-graduação brasileiro ao do México, por exemplo, observa-se que ambos possuem basicamente o mesmo número de IES. No Brasil, porém, são formados aproximadamente 10.000 doutores por ano, enquanto no México esse número não ultrapassa 5.000 - o autor atribui essa diferença à maior eficiência indutiva do sistema de avaliação da CAPES.

A pós-graduação stricto sensu é reconhecidamente o componente mais bem-sucedido do sistema educacional brasileiro. Esse êxito deve-se, em gran- 
de parte, ao fato de as ações do governo brasileiro, voltadas para o desenvolvimento desse nível de ensino, terem se calcado em um processo sistemático e bem conduzido de avaliação do desempenho, inicialmente dos cursos de mestrado e de doutorado existentes no país (CAPES, 1999) e posteriormente dos programas de pós-graduação stricto sensu (CAPES, 2009). A rigor, ao estabelecer as metas e requisitos de qualidade que orientam o desenvolvimento desse nível de ensino, o sistema de avaliação conduzido pela CAPES assegurou bases sólidas ao processo de expansão e consolidação da pós-graduação nacional e contribuiu para a criação das condições essenciais para que se efetivassem grandes avanços no campo da pesquisa científica $e$ tecnológica no País.

\section{Processo de Avaliação Adotado pela CAPES}

Segundo a CAPES (2008a), o atual Sistema de Avaliação abrange dois processos: um refere-se à avaliação dos programas e o outro à avaliação das propostas de cursos novos, ambos na pós-graduação stricto sensu. Essa avaliação é conduzida por comissões formadas por pares que atuam como consultores ad hoc, selecionados pela credibilidade conquistada na área e pelo fato de serem vinculados a instituições localizadas em diferentes regiões do País.

$\mathrm{Na}$ Avaliação dos Programas de pós-graduação é feito o acompanhamento anual $e$ a avaliação trienal do desempenho de todos os programas que integram o Sistema Nacional de Pós-graduação (SNPG). O acompanhamento anual é importante uma vez que contribui para identificar possíveis desvios de performance, existente nos programas avaliados, propiciando assim sua correção durante o processo. $\mathrm{O}$ acompanhamento não implica atribuição de conceitos aos programas, apenas elaboração e apresentação de consistente parecer cujo conteúdo reúne os comentários considerados pertinentes pelo Comitê de Área. Esse processo é finalizado na avaliação trienal.

Os resultados da avaliação de cada programa são consolidados em uma ficha de Avaliação, elaborada pelo CTC, em que constam os vários quesitos $e$ itens objeto de avaliação, os atributos a ele consignados, com os respectivos comentários e justificativas da comissão avaliadora. Ao final, é emitido o conceito correspondente ao desempenho alcançado no triênio, respeitando uma escala que varia entre um e sete. Enquanto os programas que alcançarem nota inferior a três são descredenciados do sistema, aqueles que atingi- 
rem nota igual ou superior a três terão a sua renovação e reconhecimento garantidos pelo triênio subsequente. Tais resultados podem ser contestados pelas instituições de ensino, mediante a apresentação de recurso contra a decisão inicial comunicada pela CAPES. Uma vez homologado pelo Ministro da Educação, ele será válido até a ratificação dos resultados da Avaliação Trienal subsequente.

Já a Avaliação das Propostas de Cursos Novos não utiliza os mesmos procedimentos. Ao avaliar as propostas submetidas, a CAPES verifica se elas atendem ao padrão de qualidade estabelecido para esse nível de formação $e$ posteriormente encaminha os resultados da avaliação para, nos termos da legislação vigente, fundamentar a deliberação do Conselho Nacional de Educação (CNE), vinculado ao Ministério da Educação (MEC) sobre o reconhecimento de cursos e sua incorporação ao SNPG.

Observa-se que os dois processos - tanto a avaliação dos programas quanto a avaliação das propostas de novos programas - são alicerçados em um mesmo conjunto de princípios, diretrizes e normas, compondo, assim, um só sistema de avaliação (CAPES, 2008b).

\section{Parâmetros que Integram o Sistema de Avaliação da CAPES}

No início de 2009 existiam 97 programas de pós-graduação credenciados pela CAPES nas áreas de Administração, Contabilidade e Turismo, envolvendo 122 cursos no total, sendo 71 de mestrado, 25 de doutorado e 26 de mestrado profissionalizante (CAPES, 2009).

Apesar de o sistema de avaliação da pós-graduação brasileira ser o mesmo para todas as áreas, o Comitê de Avaliação da área de Administração tem a flexibilidade de alterar o peso dos critérios em até $5 \%$ para mais ou para menos. Além disso, é livre para modificar os pesos dos itens no interior de cada critério ou ainda suprimi-lo caso ele não se aplique às necessidades da área de Administração.

Atualmente, a fundação adota cinco critérios de avaliação e cada um tem peso diferente na composição da nota final: proposta do programa (1); corpo docente (2); corpo discente (3); produção intelectual (docente e discente) (4), e inserção social (5). Cada critério é desdobrado em itens - a 
Tabela 1 consolida todos os itens subordinados a cada um dos critérios utilizados pelo sistema de avaliação da CAPES.

Tabela 1: Critérios da avaliação.

\begin{tabular}{|c|c|c|c|c|c|c|c|}
\hline \multirow[b]{2}{*}{ Critérios } & \multirow{2}{*}{\multicolumn{2}{|c|}{$\begin{array}{l}\text { Desdobramento } \\
\text { de cada quesito }\end{array}$}} & \multicolumn{5}{|c|}{ Avaliação } \\
\hline & & & 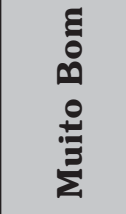 & ๓̊ & పై & $\begin{array}{l}\text { : } \\
\text { E }\end{array}$ & 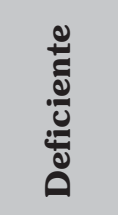 \\
\hline \multirow{4}{*}{$\begin{array}{c}\text { Proposta do } \\
\text { programa }\end{array}$} & \multicolumn{2}{|c|}{$\begin{array}{l}\text { Áreas de concen- } \\
\text { tração, linhas de } \\
\text { pesquisa e projetos } \\
\text { em andamento } \\
\text { (pesquisa, desen- } \\
\text { volvimento e } \\
\text { extensão). }\end{array}$} & \multirow{4}{*}{\multicolumn{5}{|c|}{ Avaliação Qualitativa }} \\
\hline & \multicolumn{2}{|c|}{$\begin{array}{l}\text { Coerência, consis- } \\
\text { tência e } \\
\text { abrangência da } \\
\text { estrutura curricular. }\end{array}$} & & & & & \\
\hline & \multicolumn{2}{|c|}{$\begin{array}{l}\text { Infraestrutura para } \\
\text { ensino, pesquisa e } \\
\text { extensão. }\end{array}$} & & & & & \\
\hline & \multicolumn{2}{|c|}{$\begin{array}{l}\text { Atividades inovado- } \\
\text { ras e diferenciadas } \\
\text { de formação de } \\
\text { docentes. }\end{array}$} & & & & & \\
\hline \multirow{2}{*}{$\begin{array}{l}\text { Corpo } \\
\text { Docente }\end{array}$} & $15 \%$ & $\begin{array}{l}\text { Formação dos } \\
\text { docentes } \\
\text { permanentes. }\end{array}$ & $\geq 80 \%$ & $70-79 \%$ & $60-69 \%$ & $50-59 \%$ & $<50 \%$ \\
\hline & $25 \%$ & $\begin{array}{l}\text { Adequação da } \\
\text { dimensão, } \\
\text { composição e } \\
\text { dedicação dos } \\
\text { docentes } \\
\text { permanentes. }\end{array}$ & $>70 \%$ & $61-70 \%$ & $51-60$ & $40-50 \%$ & $<40 \%$ \\
\hline
\end{tabular}

Fonte: Elaborado a partir de Becker (2008). 
Tabela 1: Critérios da avaliação.

\begin{tabular}{|c|c|c|c|c|c|c|c|}
\hline \multirow[b]{2}{*}{ Critérios } & \multirow{2}{*}{\multicolumn{2}{|c|}{$\begin{array}{l}\text { Desdobramento } \\
\text { de cada quesito }\end{array}$}} & \multicolumn{5}{|c|}{ Avaliação } \\
\hline & & & छี & & పే & & $\stackrel{\Perp}{\Xi}$ \\
\hline \multirow{3}{*}{$\begin{array}{l}\text { Corpo } \\
\text { Docente }\end{array}$} & $20 \%$ & $\begin{array}{l}\text { Perfil do corpo } \\
\text { permanente } \\
\text { em relação à } \\
\text { proposta do } \\
\text { programa. }\end{array}$ & $\geq 80 \%$ & $70-79 \%$ & $60-69 \%$ & $50-59 \%$ & $<50 \%$ \\
\hline & $10 \%$ & $\begin{array}{l}\text { Atividade } \\
\text { docente } \\
\text { permanente na } \\
\text { pós-graduação. }\end{array}$ & $>90 \%$ & $80-89 \%$ & $70-79 \%$ & $60-69 \%$ & $<60 \%$ \\
\hline & $10 \%$ & $\begin{array}{l}\text { Atividade } \\
\text { docente } \\
\text { permanente na } \\
\text { graduação. }\end{array}$ & $\geq 90 \%$ & $80-89 \%$ & $70-79 \%$ & $60-69 \%$ & $<60 \%$ \\
\hline $20 \%$ & $20 \%$ & $\begin{array}{l}\text { Participação } \\
\text { dos docentes } \\
\text { em pesquisa e } \\
\text { desenvolvi- } \\
\text { mento de } \\
\text { projetos. }\end{array}$ & $\geq 90 \%$ & $80-89 \%$ & $70-79 \%$ & $60-69 \%$ & $<60 \%$ \\
\hline \multirow[t]{2}{*}{$\begin{array}{c}\text { Corpo } \\
\text { Discente } \\
\text { Teses e } \\
\text { Dissertações }\end{array}$} & $20 \%$ & $\begin{array}{l}\text { Percentual de } \\
\text { defesas } \\
\text { mestrado/ } \\
\text { doutorado em } \\
\text { relação ao } \\
\text { corpo docente } \\
\text { permanente. }\end{array}$ & $\begin{array}{l}\geq 40 \% \\
\geq 25 \%\end{array}$ & $\begin{array}{l}36-39 \% \\
22-24 \%\end{array}$ & $\begin{array}{l}30-35 \% \\
18-21 \%\end{array}$ & & $\begin{array}{l}<30 \% \\
<18 \%\end{array}$ \\
\hline & $15 \%$ & $\begin{array}{l}\text { Adequação e } \\
\text { compatibilida- } \\
\text { de da relação } \\
\text { orientador/ } \\
\text { discente. }\end{array}$ & $\leq 8$ & & & & $<8$ \\
\hline
\end{tabular}

Fonte: Elaborado a partir de Becker (2008). 
Tabela 1: Critérios da avaliação.

\begin{tabular}{|c|c|c|c|c|c|c|c|}
\hline \multirow[b]{2}{*}{ Critérios } & \multirow{2}{*}{\multicolumn{2}{|c|}{$\begin{array}{l}\text { Desdobramento } \\
\text { de cada quesito }\end{array}$}} & \multicolumn{5}{|c|}{ Avaliação } \\
\hline & & & 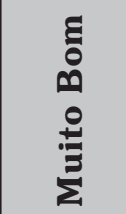 & है & 突 & : & 苋 \\
\hline \multirow{3}{*}{$\begin{array}{c}\text { Corpo } \\
\text { Discente } \\
\text { Tesese } \\
\text { Dissertações }\end{array}$} & $10 \%$ & $\begin{array}{l}\text { Participação } \\
\text { de discentes } \\
\text { autores da } \\
\text { pós-graduação } \\
\text { e graduação. }\end{array}$ & $\begin{array}{l}\geq 25 \% \\
\geq 40 \%\end{array}$ & $\begin{array}{l}20-24,9 \% \\
30-39,9 \%\end{array}$ & $\begin{array}{l}15-19,9 \% \\
20-29,9 \%\end{array}$ & $\begin{array}{l}10-14,9 \% \\
10-19,9 \%\end{array}$ & $<10 \%$ \\
\hline & $20 \%$ & $\begin{array}{l}\text { Dissertações/ } \\
\text { teses vincula- } \\
\text { das a publica- } \\
\text { ções. }\end{array}$ & $\begin{array}{l}>50 \% \\
>80 \%\end{array}$ & $\begin{array}{l}40-50 \% \\
60-80 \%\end{array}$ & $\begin{array}{l}30-40 \% \\
40-60 \%\end{array}$ & $\begin{array}{l}20-30 \% \\
30-40 \%\end{array}$ & $\begin{array}{l}<20 \% \\
<30 \%\end{array}$ \\
\hline & $20 \%$ & $\begin{array}{l}\text { Qualidade das } \\
\text { teses e disser- } \\
\text { tações. }\end{array}$ & \multicolumn{5}{|c|}{ Avaliação Qualitativa } \\
\hline $35 \%$ & $15 \%$ & $\begin{array}{l}\text { Tempo médio } \\
\text { de titulação de } \\
\text { mestres e } \\
\text { doutores. }\end{array}$ & $\begin{array}{l}<30 \\
<54\end{array}$ & $\begin{array}{l}30-31 \\
54-55\end{array}$ & $\begin{array}{l}32-33 \\
55-56\end{array}$ & & $\begin{array}{l}>33 \\
>56\end{array}$ \\
\hline \multirow{3}{*}{$\begin{array}{l}\text { Produção } \\
\text { Intelectual }\end{array}$} & $50 \%$ & $\begin{array}{l}\text { Publicações } \\
\text { qualificadas } \\
\text { do programa } \\
\text { por docente } \\
\text { permanente. }\end{array}$ & $>50$ & $35-49$ & $20-34$ & $12-19$ & $<12$ \\
\hline & $20 \%$ & $\begin{array}{l}\text { Distribuição de } \\
\text { publicações } \\
\text { qualificadas } \\
\text { em relação ao } \\
\text { corpo docente } \\
\text { permanente. }\end{array}$ & $>80 \%$ & $70-80 \%$ & $50-70 \%$ & $20-50 \%$ & $<20 \%$ \\
\hline & $15 \%$ & $\begin{array}{l}\text { Produção } \\
\text { técnica ou } \\
\text { tecnológica. }\end{array}$ & \multicolumn{5}{|c|}{ Avaliação Qualitativa } \\
\hline
\end{tabular}

Fonte: Elaborado a partir de Becker (2008). 
Tabela 1: Critérios da avaliação.

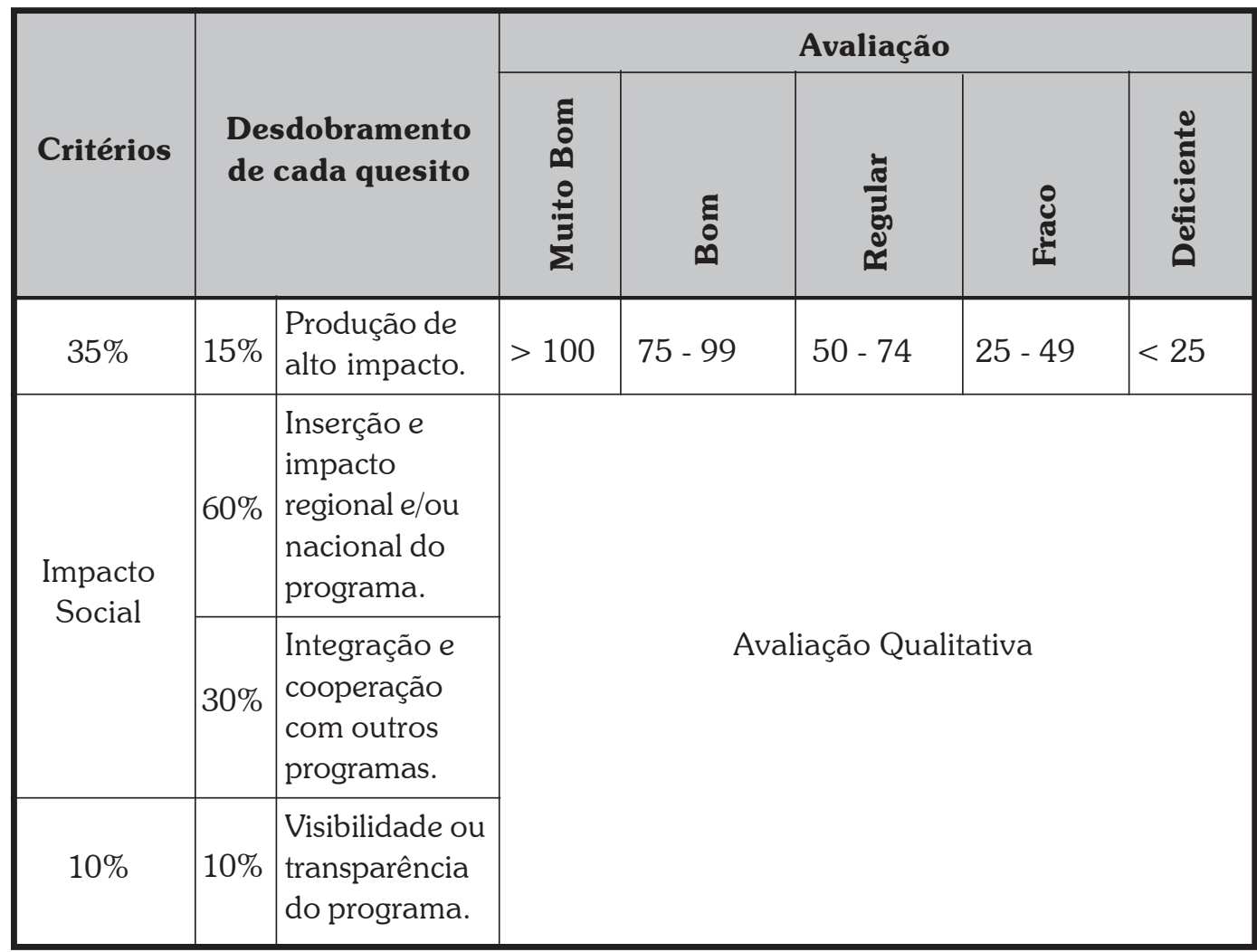

Obs: No critério Discentes/Dissertações e Teses os números em vermelho referem-se aos indicadores utilizados para avaliar o curso de mestrado, já os números em azul são utilizados para avaliar o curso de doutorado, os números em preto servem para avaliar tanto os cursos de mestrado quanto os de doutorado.

Fonte: Elaborado a partir de Becker (2008).

O critério proposta do programa é qualitativo e não possui peso na avaliação é interpretada como Adequada ou inadequada. Destaca-se que é neste critério que os programas descrevem suas Área(s) de concentração, linhas de pesquisa e projetos em andamento (pesquisa, desenvolvimento $e$ extensão). É também verificado a coerência, consistência e abrangência da estrutura curricular, bem como a Infraestrutura para ensino, pesquisa e extensão e as Atividades inovadoras e diferenciadas de formação de docentes.

Apesar de o critério corpo docente representar $20 \%$ no peso total da avaliação, parece ser o mais importante uma vez que tem o poder de influenciar diretamente os resultados dos demais critérios da avaliação. Esse critério é composto pelos seguintes itens: Formação dos docentes permanentes; Ade- 
quação da dimensão, composição e dedicação dos docentes permanentes; Perfil do corpo permanente em relação à proposta do programa; Atividade docente permanente na pós-graduação; Atividade docente permanente na graduação; Participação dos docentes em pesquisa e desenvolvimento de projetos.

O critério corpo discente/Teses e Dissertações - representar 35\% do total da avaliação. Observa-se que houve um aumento de peso deste critério para o triênio 2007-2009 em relação ao triênio 2004-2006, passando de $25 \%$ para $35 \%$. Esse critério é composto pelos itens: Percentual de defesas mestrado/doutorado em relação ao corpo docente permanente; Adequação e compatibilidade da relação orientador/discente; Participação de discentes autores da pós-graduação e graduação; Dissertações/teses vinculadas a publicações; Qualidade das teses e dissertações; Tempo médio de titulação de mestres e doutores.

Produção intelectual corresponde a $35 \%$ do peso da avaliação e é decisivo no momento da atribuição da nota pela CAPES. Esse critério é composto pelos itens: Publicações qualificadas do programa por docente permanente; Distribuição de publicações qualificadas em relação ao corpo docente permanente; Produção técnica ou tecnológica; Produção de alto impacto. Nesse critério é avaliado os itens de qualidade e quantidade de publicações dos docentes, com regra para produção mínima para cada nível de nota do programa.

Finalmente, o critério inserção social representando $10 \%$ no peso total da avaliação e destaca-se o seu caráter qualitativo. Esse critério é composto pelos seguintes itens: inserção e impacto regional (e/ou nacional) do programa; integração e cooperação com outros programas; e visibilidade e transparência do programa. Verifica-se a indução do sistema de avaliação da CAPES para que os programas ampliem a inserção social. Isso fica evidente quando se observa as exigências de inserção social para os programas com nota 6 e 7 .

\section{Descrição dos Recursos Metodológicos Explorados}

Segundo Hughes (1983), a teoria, a metodologia e a prática caminham juntas e operam dentro de determinado conjunto de suposições sobre a natureza da sociedade e do homem, sobre a relação entre os dois e sobre como 
podem ser conhecidos. Nessa linha, Lakatos et al. (1991) indicam que o método consubstancia-se a partir de procedimentos sistemáticos e racionais que permitem elaborar conhecimentos legítimos, pois são passíveis de fundamentação. Tanto quanto nos demais campos, as pesquisas na área da Administração observam procedimentos característicos da investigação científica, imprimindo sistematização à coleta, registro, seleção e tratamento dos materiais; critérios sólidos na seleção de autores e textos, de modo que os exercícios interpretativos e analíticos legitimem as conclusões alcançadas e, dessa forma, contribuam para melhor compreensão de atitudes, comportamentos e decisões que cercam as organizações (COOPER; SCHINDLER, 2003).

Nesse sentido, optou-se por utilizar a pesquisa qualitativa exploratória, que, de acordo com Eisenhardt (1989), viabiliza estudos com dados qualitativos, os quais são particularmente úteis quando se quer entender o porquê do relacionamento entre variáveis. Dessa forma, ponderou-se que esse tipo de pesquisa possui o potencial para atender, de maneira satisfatória, aos interesses dos pesquisadores em se obter informações relevantes, resultantes do levantamento em profundidade dos dados, possibilitando conhecer melhor determinado fenômeno (YIN, 2003; VAN MAANEN, 1988). Optou-se pelo uso do estudo de caso, com a análise de múltiplos casos, devido ao fato de esse tipo de análise tornar os resultados mais robustos e, guardando suas peculiaridades, passíveis de generalização (HERRIOTT; FIRESTONE, 1983).

Operacionalmente, realizou-se uma pesquisa de campo por meio de visitas e entrevistas roteirizadas com os coordenadores responsáveis pelos programas selecionados como unidades sociais de estudo. $\mathrm{O}$ objetivo nuclear de tais contatos residia em identificar a influência exercida pelo uso do sistema de avaliação da pós-graduação da CAPES (particularmente os critérios de avaliação corpo docente, corpo discente e inserção social) sobre o desenvolvimento dos programas, tendo como base o constructo previamente elaborado. Para a confecção do constructo se levou em consideração as recomendações de Eisenhardt (1989), Miles e Huberman (1994) visando elaborar um instrumento de coleta de dados que traduzisse as características presentes no sistema de avaliação adotado no Brasil. O Quadro 1 sumariza o constructo utilizado. 


\begin{tabular}{|l|l|c|}
\hline \multicolumn{1}{|c|}{ Cluster } & \multicolumn{1}{|c|}{ Análise dos Componentes Principais } & Quest. BRA \\
\hline \multirow{5}{*}{ Corpo Docente } & Contratação de docentes & 1 \\
\cline { 2 - 3 } & Fluxo de docentes & 2 \\
\cline { 2 - 3 } & Equilíbrio das atividades & 3 \\
\cline { 2 - 3 } & Auxílio para produção intelectual & 4 \\
\cline { 2 - 3 } & Política para financiamento & 5 \\
\hline \multirow{5}{*}{ Discentes/Egressos } & Influência do sistema na formação, tempo médio de titulação & 6 \\
\cline { 2 - 3 } & Incentivo para produção discente & 7 \\
\cline { 2 - 3 } & Acompanhamento discente & 8 \\
\cline { 2 - 3 } & Acompanhamento do egresso & 10 \\
\hline \multirow{2}{*}{ Inserção social } & Ações para melhorar a inserção social & 11 \\
\cline { 2 - 3 } & Influência para a internacionalização & 9 \\
\hline
\end{tabular}

Quadro 1: Constructo da pesquisa.

Fonte: Elaborado pelos autores.

\subsection{Procedimentos de Análise dos Dados}

Para Miles, Huberman (1994) e Eisenhardt (1989) a análise dos resultados tem particular importância para o método de estudos de caso por envolver procedimentos mais complexos na medida em que requer a construção de categorias de análise. Uma vez que para os autores (MILES; HUBERMAN, 1994), a análise de dados qualitativos, em um estudo de múltiplos casos, requer a utilização de técnicas que facilitem a compreensão, síntese e sumarização dos resultados. Para que isso seja possível, é fundamental que o instrumento de coleta seja o mesmo, a fim de possibilitar a comparação. Isso significa que questões, códigos de dados, variáveis e apresentação dos resultados devem ser convergentes. Os autores sugerem a criação de metamatriz que possibilite sintetizar e agrupar os dados em clusters.

\subsection{Definição das Unidades Sociais de Estudo}

Levando-se em conta que a pesquisa foi desenvolvida de acordo com os procedimentos típicos do método de estudo de caso múltiplo, um dos desafios foi a seleção das unidades sociais de estudo, ver Quadro 2. 


\begin{tabular}{|c|c|c|c|c|}
\hline Universidade & Caract. & Ano Cred. & Cursos & Conceito \\
\hline $\begin{array}{l}\text { Programa de pós-graduação em } \\
\text { Administração da Universidade de } \\
\text { São Paulo - USP }\end{array}$ & Pública & 1975 & $\mathrm{M} / \mathrm{D}$ & 6 \\
\hline $\begin{array}{l}\text { Programa de pós-graduação em } \\
\text { Administração da Universidade } \\
\text { Federal do Rio Grande do Sul - } \\
\text { UFRGS }\end{array}$ & Pública & $1972 / 1994 *$ & $\mathrm{M} / \mathrm{D}$ & 6 \\
\hline $\begin{array}{l}\text { Programa de pós-graduação em } \\
\text { Administração da Universidade } \\
\text { Regional de Blumenau - FURB }\end{array}$ & Pública & 1997 & $\mathrm{M} / \mathrm{D}$ & 4 \\
\hline $\begin{array}{l}\text { Programa de pós-graduação em } \\
\text { Administração da Universidade } \\
\text { Nove de Julho - UNINOVE }\end{array}$ & Privada & 2001 & $\mathrm{M} / \mathrm{D}$ & 4 \\
\hline
\end{tabular}

Legenda: *Início do Doutorado.

Quadro 2: Programas de pós-graduação na área de Administração no Brasil recomendados pela CAPES.

Fonte: Elaborado pelos autores.

Trabalhou-se com quatro programas de pós-graduação em Administração, oferecidos por instituições públicas e privadas, distribuídas em diferentes regiões do País, com tradição acadêmica em diferentes estágios: dois programas são oferecidos por tradicionais universidades públicas (Universidade de São Paulo/USP e Universidade Federal do Rio Grande do Sul/UFRGS). Ambos possuem reconhecida notabilidade na pós-graduação e participam do sistema de avaliação da CAPES. Além disso, por dois triênios consecutivos alcançaram o conceito seis.

O terceiro programa é igualmente oferecido por uma universidade pública (Universidade Regional de Blumenau/FURB) e o quarto por uma universidade privada (Universidade Nove de Julho/UNINOVE). No triênio 20042006 , esses dois programas obtiveram conceito quatro $e$ foram considerados de nível bom. Sinalizando claro amadurecimento institucional e acadêmico, em 2007 e em 2008, respectivamente, a UNINOVE e a FURB tiveram autorização da CAPES para oferecer o doutorado em Administração. 


\section{Análise e Discussão dos Resultados}

Para responder à pergunta de pesquisa deste artigo: como o sistema de avaliação adotado pela CAPES vem sendo utilizado pelos programas de pósgraduação stricto sensu em Administração, no Brasil? E de que modo ele tem colaborado para o fortalecimento de tais programas? Optou-se por separar as respostas dos Coordenadores de programas em três clusters: Corpo Docente; Corpo Discente/Egresso e Inserção Social

\subsection{Corpo Docente}

Ao se interpretar as narrativas dos coordenadores, percebe-se que o sistema de avaliação da CAPES tem se revelado grande influenciador na contratação de docentes pelos programas. O aspecto determinante da contratação dos docentes é a produção intelectual subordinada às linhas de pesquisas priorizadas pelo programa (exigência do sistema de avaliação da CAPES). Observam-se tanto a consistência (qualidade) quanto o número de publicações (quantidade) do candidato a docente. A necessidade de novas contratações de docentes ocorre para cobrir lacunas identificadas ou para desenvolver novas linhas que o programa deseja criar.

Em relação ao fluxo de docentes no programa, os coordenadores entendem que ele depende diretamente da produção intelectual ou da potencialidade da referida produção. Compreensivelmente, os coordenadores de programas exercem forte pressão sobre os professores para que produzam e publiquem artigos e livros. Apenas dessa forma terão condições de atender às metas estabelecidas pelo sistema de avaliação para cada nível de nota. Assim, os professores do corpo permanente que não conseguirem atingir o patamar estabelecido no triênio passam a figurar como colaboradores ou podem até ser desligados do quadro de professores do programa. Contrariamente, os professores colaboradores que apresentarem compatibilidade com o patamar exigido de publicações podem vir a fazer parte do corpo permanente do programa.

Ao olhar de perto as ações orientadas para a elevação da melhoria da qualidade e da quantidade da produção intelectual dos docentes, pode-se perceber diferenças entre os grupos de programas maiores e mais antigos (USP e UFRGS) e entre os menores e mais novos (FURB e UNINOVE). Entre 
os programas que integram o primeiro grupo (USP e UFRGS), os professores mais produtivos, ou seja, aqueles que pesquisam, elaboram textos e publicam em periódicos internacionais e nacionais, recebem incentivos financeiros, são homenageados e têm o reconhecimento dos pares e da academia.

Para os programas da FURB e UNINOVE, os professores mais produtivos são estimulados a estabelecer parcerias com os discentes e usufruem de condições de trabalho capaz de auxiliá-los na produção de novos textos. O responsável pelo programa da FURB, por exemplo, destacou a importância da participação em congressos por reconhecer as reuniões acadêmicas um veículo de divulgação dos resultados das pesquisas concluídas. Já o programa da UNINOVE utiliza-se do constante acompanhamento da produção do docente, como forma de "lembrar" os professores da necessidade da produção intelectual. A instituição formulou um ranking interno de produtividade acadêmica e divulgou. Com isso, assegura que houve expressiva mudança de atitude entre alguns professores uma vez que a publicização dos resultados individuais valorizou os produtivos e advertiu os improdutivos.

Curiosamente, os coordenadores dos programas investigados não fizeram qualquer menção à produção técnica dos docentes. Possivelmente essa aparente desimportância da atividade se deva ao fato de ser um item avaliado por um crivo qualitativo e até o momento não dispõe de suficiente definição acerca de quais produções técnicas são efetivamente importantes e merecem ser destacadas e valorizadas.

A partir da nota cinco, o sistema de avaliação da CAPES exige que determinado número de docentes permanentes seja bolsista de produtividade do $\mathrm{CNPq}$ ou coordene projetos de pesquisas financiados por agências de fomento estadual, nacional ou internacional. Há expectativas de que o número de professores que assume tais responsabilidades seja ampliado na medida em que o programa alcançar notas mais elevadas. A título de exemplificação, em um programa que obtiver nota cinco é exigido que $10 \%$ dos docentes permanentes sejam bolsistas de produtividade ou coordenem projetos financiados por alguma agência de fomento; esse número se eleva para $25 \%$ em programas que obtiverem nota seis, e para $40 \%$ em programas que conquistarem nota sete. Fica claro, portanto, porque os responsáveis pelos programas mais bem avaliados se preocupam tanto em ampliar o número de professores inscritos nessas categorias.

A importância da captação de bolsas de pesquisa para o programa levou a FEA-USP a investir na criação de uma equipe interna de apoio aos 
professores que desejam obter financiamento de agências públicas de fomento à pesquisa. No entanto, o coordenador do referido programa chama atenção para a necessidade de a CAPES valorizar a obtenção de recursos oriundos de outras fontes financiadoras. Segundo ele, a preocupação em diversificar as fontes de recursos para a pesquisa seria particularmente bemvinda quando se sabe que os recursos disponíveis são escassos, e quanto mais os programas conseguirem recursos de fontes não estatais, melhor seria para o sistema como um todo, pois sobrariam mais recursos para os demais programas, particularmente para os menores e mais jovens.

Na UFRGS existe uma comissão de pesquisa que se encarrega de informar aos professores sobre os editais de financiamento publicados pelas agências de fomento. Por se tratar de um programa criado em 1972 é possível reconhecer a existência de uma cultura de solicitação de financiamento às agências públicas de fomento, instalada entre os professores. De acordo com o depoimento do coordenador do programa, essa prática está s arraigada entre os membros do corpo docente e corresponde a um dos motivos pelos quais a UFRGS possui significativo número de projetos financiados por agências públicas.

Nos programas da FURB e da UNINOVE, este indicador não é uma exigência formal por parte do sistema de avaliação visto que não ultrapassaram a nota quatro na avaliação que participaram. Contudo, destaca-se que os professores do programa da UNINOVE já vêm trabalhando nessa direção, de maneira mais sistemática e estruturada.

\subsection{Corpo Discente/Egresso}

O sistema de avaliação da CAPES exerce forte influência sobre os programas ao valorizarem particularmente dois itens: tempo médio de titulação e produção discente. Todos os coordenadores asseguraram que estão atentos a essas questões e se empenham para que o programa crie as condições necessárias para que o estudante conclua o curso dentro do prazo estipulado pelo sistema: até 30 meses no caso do mestrado e até 54 no caso do doutorado.

Os programas investigados desenvolveram diversos mecanismos para estimular a produção discente, seja na forma de incentivos financeiros, validação de créditos ou por meio de exigências formais estipuladas no regulamento dos programas. Isso comprova que o discente também sofre pressões para produção advinda de professores que precisam cumprir uma cota de 
produção anual. Nesse sentido, o sistema de avaliação estimula a realização de pesquisa e a publicação de resultados em pares, ou seja, entre docentes e discentes, uma vez que a produção desenvolvida em parceria conta tanto para o critério produção docente quanto para o critério produção discente.

Apesar de o sistema de avaliação da CAPES priorizar resultados, os programas precisam estabelecer e respeitar processos internos, no intuito de atingir as exigências de resultados estipulados pelo sistema. Nessa direção, quando se avalia a exigência do sistema de avaliação para que os programas se revelem eficientes, os mecanismos de acompanhamento do estudante e respectivas atividades no âmbito do programa são criados. A FEA-USP, por exemplo, criou uma espécie de classificação dos estudantes respeitando três categorias: adequado, alerta e risco.

A UFRGS instituiu um conselho de classe para avaliar o desempenho dos estudantes. Nos casos da FURB e da UNINOVE há explícita subordinação dos projetos de pesquisa dos estudantes aos projetos de pesquisa do professor e às linhas de pesquisa do programa. Medida que apenas reflete uma das exigências do sistema de avaliação.

O sistema de avaliação da CAPES ainda não inclui informações acerca dos egressos nos critérios ou itens considerados. Por ainda não figurar um critério ou item de avaliação formalmente instituído pela Fundação, os programas ainda não estabeleceram qualquer sistemática de acompanhamento das atividades dos ex-alunos, apesar de tal ação possibilitar avaliações mais apuradas acerca do impacto do curso na trajetória profissional do egresso e da pertinência do programa às demandas da sociedade. Apenas embrionariamente alguma coisa é feita pelas coordenações.

\subsection{Inserção Social}

Os coordenadores contatados atestam que a preocupação com a inserção social do programa vem sendo estimulada pelo sistema de avaliação da CAPES e afirmam que estão realizando ações no sentido de atender às demandas do sistema para esse quesito. De forma visível, percebe-se que os programas estão investindo no desenvolvimento de projetos para a oferta de mestrados e doutorados interinstitucionais (Minter e Dinter) em outras regiões do País, com ênfase nas regiões mais carentes (também estimuladas pelo sistema). 
Constata-se que tal ação é mais contundente entre os programas mais maduros e respeitados porque há forte demanda no sentido de ampliarem o número de projetos implantados. Contudo, o coordenador do programa da FEA-USP assegurou que faltam mecanismos (por parte da CAPES) empenhados em ampliar e garantir a oferta de vagas para estudantes provenientes de regiões mais carentes. Além disso, coloca em dúvida a disponibilidade de recursos que viabilizariam a implantação e desenvolvimento dos programas interinstitucionais.

De acordo com o coordenador do programa da UFRGS, o desafio envolvido na ampliação da inserção social do programa recai sobre o fato de a CAPES impor limites na oferta de cursos fora da sede, por parte dos programas de pós-graduação. E, curiosamente, existe o mesmo tratamento para programas modestos (com uma média de 12 docentes) e um programa maior (que reúne uma média de 40 docentes). Portanto, desconfia-se de que não há estímulo para que o programa cresça recebendo um número maior de professores e estudantes ou que atue em regiões desprovidas de pós-graduação ou que tenha programas pequenos e com inconsistências importantes.

Os programas da FURB e da UNINOVE também estão se articulando para participar do Minter e Dinter, respectivamente. Apesar de todos os programas imputarem importância à formação de recursos humanos para atender às demandas sociais, regionais e nacionais, o sistema de avaliação ainda atribui pouco peso a esse critério.

A internacionalização do programa é um dos itens do sistema de avaliação para aqueles programas que alcançaram conceitos seis e sete. Nesses casos, há expectativas de que o programa apresente um nível de qualificação, de produção e de desempenho equivalentes ao dos centros internacionais de excelência na formação de recursos humanos.

Assim, para os programas com nota seis é mandatória a fixação de convênios internacionais ativos e com resultados evidenciados (a); a existência de professores visitantes oriundos de universidades estrangeiras, reputadas como de primeira linha (b); a organização de programas de intercâmbio (de mão dupla) que promovam a mobilidade estudantil com universidades estrangeiras (c); a participação do programa na organização de eventos internacionais, tanto no Brasil quanto no exterior (d); a participação de docentes do programa em comitês e diretorias de associações internacionais $(e) ; e$ publicação em periódicos internacionais $\mathrm{A}$ ou $\mathrm{B}$ no triênio por parte de pelo menos $25 \%$ dos docentes permanentes (f). 
Para a atribuição da nota sete, o programa deverá cumprir todos os itens anteriores, mas deverá elevar para $40 \%$ o número de docentes permanentes com publicação internacional - razão pela qual esse resultado está restrito a poucos programas de pós-graduação, independentemente da área de conhecimento.

Com a inclusão desses itens, o sistema de avaliação da CAPES induz os programas considerados de excelência a atuarem em esfera internacional. Os resultados dessa medida significam visibilidade para o País, reconhecimento internacional para a universidade, o programa, os professores e egressos do curso.

Sendo assim, aqueles programas que desejarem melhorar sua nota terão de oferecer condições para professores e estudantes publicarem em periódicos internacionais. Os programas da FEA-USP e da UFRGS desenvolveram ações bem-sucedidas no sentido de aumentarem a publicação internacional. Investiram, igualmente, na ampliação dos programas de intercâmbio com universidades estrangeiras, criaram incentivos para a formação de networking entre os professores, com o objetivo de fortalecer a criação de parceria que favoreçam a publicação internacional. Evidentemente, esses programas têm estímulos financeiros para os professores que publicam em periódicos internacionais.

Não há qualquer exigência por parte do sistema de avaliação da CAPES que programas avaliados com nota quatro - é o caso dos programas da FURB e da UNINOVE - tenham produção em periódicos internacionais. Contudo, percebe-se algum esforço neste sentido, uma vez que há compreensão de que esse é o caminho que consolidará os programas no médio e longo prazo.

\section{Considerações Finais}

O processo de avaliação contribui para o progresso de uma nação, fornecendo indicadores da qualidade da educação. Porém, o sistema de avaliação poderá efetivamente consubstanciar o desenvolvimento de um programa ou área quando houver consenso sobre os tipos de evidências a serem aceitas e clareza nos objetivos do sistema desenvolvido (ALLEN, 1996).

Ao buscar entender o sistema de avaliação da pós-graduação utilizado pela CAPES e o sua utilização por parte dos programs de pós-graduação, 
nota-se que os critérios e itens de avaliação estão bem definidos e são conhecidos pela comunidade acadêmica avaliada. Nesse sentido, é inegável a influência que o sistema de avaliação exerce sobre o desenvolvimento dos programas de pós-graduação em Administração do Brasil.

Verifica-se que os níveis de qualidade exigidos pelos parâmetros do sistema ajudam a melhorar o desempenho individual de um programa, ou seja, quando a CAPES estabelece as diretrizes da avaliação, dimensiona as metas e especifica as métricas de sistema de avaliação, tudo isso permite aos programas identificar as exigências de qualidade a serem alcançadas, bem como a participação de cada um no desenvolvimento local, regional e nacional.

Assim, na visão dos coordenadores dos programas investigados, o sistema de avaliação tem influenciado os programas nos seguintes aspectos:

a) Direcionador estratégico dos programas: o sistema de avaliação é considerado como o indutor das ações e metas que serão estabelecidas e colocadas em prática pelos programas para o seu pleno desenvolvimento. Os parâmetros do sistema influenciam na definição dos requisitos para contratação dos docentes e sua atuação, principalmente no que diz respeito à produção intelectual e à formação acadêmica dos estudantes.

b) Qualidade: sob o ponto de vista dos requisitos de qualidade mínima para um programa de pós-graduação, o sistema de avaliação da CAPES tem ajudado, indistintamente, os programas a direcionarem seus esforços e investimentos, tanto para a infraestrutura quanto para a produção intelectual docente e discente, conduzindo-os a um melhor desempenho.

c) Produtividade: a natureza essencialmente quantitativa do sistema de avaliação da CAPES induz à produtividade e equilibra os papéis e funções dos constituintes do programa. Por um lado, o sistema incita a um alto desempenho quantitativo em termos de produção intelectual, geração de pesquisa e formação discente; por outro, induz à observância exclusiva dos critérios quantitativos requeridos pelo sistema de avaliação.

d) Inserção social: o sistema tem direcionado os programas a ampliarem sua inserção e impacto social. Isso é observado tanto nas exigências de formação de recursos humanos altamente qualificados 
quanto da participação dos programas no desenvolvimento da pósgraduação em regiões que apresentam carência de cursos de mestrado e doutorado.

Por fim, devido à natureza e constituição, o sistema da CAPES tem ajudado a garantir a qualidade mínima e a direcionar novos programas incipientes e inexperientes - a uma rápida consolidação, porém, não estimula os programas grandes e consolidados a ampliarem seu escopo de competências e suas contribuições no âmbito da inserção social.

Por mais óbvio que seja, parece oportuno lembrar que a CAPES não está dissociada dos programas, uma vez que a definição das políticas de pósgraduação, em geral, da filosofia e sistemática do sistema de avaliação, em particular, são definidas e concretizadas pelos professores dos programas de pós-graduação. Sendo assim, é impossível que o sistema de avaliação, em qualquer tempo, não traduza os valores acadêmicos das áreas de conhecimento avaliadas e as convicções dos pares.

\section{The use of the CAPES Evaluation System by Graduate Business Programs in Brazil}

\section{Abstract}

The Brazilian evaluation system of graduate programs has been improving since 1976 and is considered one of the most modern systems in the world. This system has become the principal guide to the development of graduate programs in Brazil. The goal of this study is to investigate how the CAPES evaluation system has been incorporated into graduate business programs in Brazil and how it has been used in the collaboration of the strengthening of the programs. The method used was a multiple case study which allowed intensive research in four specific units of public and private graduate business programs in different stages of development. As a result it was found that: 1) the evaluation system has great influence on the development of the programs and is their principal strategic guide; 2) the criteria and items of evaluation are well defined and the academic community is aware of them; 3 ) the system demands high quality and productivity and encourages the expansion and inclusion of these programs into the community.

Key-words: Evaluation. Graduate Evaluate. Evaluation System. CAPES Evaluation System. 


\section{Referências}

AFONSO, A. J. Avaliação educacional: regulação e emancipação para uma sociologia das políticas avaliativas contemporâneas. São Paulo: Cortez, 2000.

ALEMÁN, G. C. Del. Dos modelos diferenciados de configuración institucional bajo El impacto de La evaluación externa: la UAM y la UIA. Colección Biblioteca de La Educación Superior. México: Anuies, 2005.

ALLEN, N. L. Avaliação em larga escala: lições de experiências. Brasília: MEC. SEDIAE: Fundação Cesgranrio, 1996. p. 77-99. BBE.

BECKER, J. L. Critérios aprovados pelo CTC para o triênio 2007-2009. Apresentação em PowerPoint. Rio de Janeiro, novembro de 2008.

CAPES. A reformulação do sistema de avaliação da pós-graduação brasileira. Brasília: Diretoria de Avaliação CAPES, 1999.

. CAPES 50 anos: depoimentos ao CPDOC/FGV. Organizadores Marieta de Moraes Ferreira e Regina da Luz Moreira. Brasília: CAPES, 2002, $343 \mathrm{p}$.

.Relação dos cursos reconhecidos e recomendados. Disponível em: <http://conteudoweb.capes.gov.br/conteudoweb/ ProjetoRelacaoCursosServlet?acao $=$ pesquisarArea\&codigoGrandeArea $=$ 60000007\&descricaoGrandeArea $=$ CI\%CANCIAS + SOCIAIS + APLICADAS > . Acesso em: 25 mar. 2009.

\section{Critérios de Avaliação da Área de Administração Contabili-} dade e Turismo (Triênio2004-2006). Disponível em: <http:// www.CAPES.gov.br/export/sites/CAPES/download/avaliacao/ CA2007_AdministracaoTurismo.pdf>. Acesso em: 5 abr. 2008.

. Avaliação da pós-graduação. Disponível em: http:// www.CAPES.gov.br/avaliacao/avaliacaopos.html. Acesso em: 15 maio 2008a.

. Estatística da Pós-Graduação: total de alunos geral para o ano de 2007. Disponível em: < http://ged.CAPES.gov.br/AgDw/silverstream/pages/ frPesquisaColeta.html>. Acesso em: 15 abr. 2008b. 
COOPER, D.; SCHINDLER, P. <étodos de pesquisa em administração. 7. ed. Porto Alegre: Bookman, 2003. ix 640 p. il + 1 CD-ROM. Tradução de Business research methods. Companha CD-ROM.

DI MAGGIO, P.; POWELL, W. The iron Cage revisited: institucional isomorphism and collective rationalit in organizational fields. In: POWELL; DI MAGGIO, P. The new institutionalism in organizational analysis. Chicago: Press, 1991.

DURHAM, E. R. A institucionalização da Avaliação. In: DURHAN, Eunice R.; SCHWARTZMAN, Simon (org.). Avaliação do ensino superior. São Paulo: Edusp, 1992.

. Avaliação. In: STEINER, J. E.; MALNIC, G. Ensino Superior: conceito e dinâmica. São Paulo: Edusp, 2006.

EISENHARDT, K. M. Building Theories from Case Study Research. Academy of Management Review, v. 14, n. 4, 1989.

EL-KHAWAS, E. El control de calidad en deucación superior: avances recientes dificultades por superar. Documento eleaborado com el auspicio del Banco Mundial. Conferencia Mundial sobre la Educación Superior. Paris, 1998.

FOUCAULT, Michel. Vigiar e punir: nascimento da prisão. 2. ed. Petropolis: Vozes, 1983.

GATTI, B. Reflexões sobre o desafio da Pós-graduação: novas perspectivas sociais, conhecimento e poder. In: José M. Nagamine. (Org.). Gestão acadêmica: desafios e perspectivas. 1. ed. São Paulo, SP: Ed. EDUC, 2000, p. 162-171.

. Avaliação Institucional de Universidade. In: STEINER, J. E.; MALNIC, G. (Org.). Ensino Superior: conceito e dinâmica. São Paulo: Edusp, 2006.

GAETANI, F; SCHWARTZMAN, J. Avaliação de Cursos de Graduação: um modelo de análise. USP: NUPES, 03/1993.

HERRIOTT, R. E; FIRESTONE, W. A. Multisite qualitative policy research: Optimizing description and generalizability. Educational Research, v. 12, 1983.

HOUSE, E. R. Tendencias en evaluación. Revista de Educación. Madri, n. 299, Enero-abril, 1992. 
HUGHES, John. A filosofia da pesquisa social. Rio de Janeiro: Zahar, 1983.

INFOCAPES. Boletim informativo. Brasília: CAPES, v. 4, n. 2, abril/jun. 1996.

INEP - Instituto Nacional de Estudos e Pesquisas Educacionais Anísio Teixeira. Modelos Institucionais de Ensino Superior. In: Educação em Debate. Brasília: INEP, 2006.

LAKATOS, E. M. et al. Fundamentos de metodologia científica. 3. ed. São Paulo: Atlas, 1991.

MILES, M. B.; HUBERMAN, A. M. Qualitative data analysis: an expanded sourcebook. 2. ed. Oaks, CA: Sage, 1994.

NICOLATO, Maria Auxiliadora. A evolução da concepção e da linha de ação do programa CAPES-COFECUB. InfoCAPES. Boletim Informativo. Brasília: CAPES, v. 7, 2000.

RODRIGUES, C. M. C. Proposta de avaliação integrada ao planejamento anual: um modelo para as UCGs. Tese apresentada ao Programa de PósGraduação em Engenharia de Produção da Escola de Engenharia da Universidade Federal do Rio Grande do Sul - URFGS. 341 f. Porto Alegre, 2003.

SBPC - Sociedade Brasileira Para o Progresso da Ciência. Jornal da Ciência. Ano XXII, n. 624, 27/06/2008.

SCHWARTZMAN, S. O contexto institucional e político da avaliação do ensino superior. Universidade de São Paulo: Núcleo de Pesquisas sobre Ensino Superior Universidade de São Paulo. 3/1990.

UNESCO. La educación superior en el siglo XXI: visión y acción. Conferencia Mundial sobre La Educación Superior. Paris, 1998.

VAN MAANEN, J. Tales of the Field: on writing ethnography. Chicago: University of Chicago Press, 1988.

WILLIS, D. Educational assessment and accountability: a New Zealand case study. Journal of Education Policy, v. 7. n. 2, 1992.

YIN, R. Case study research: design and methods. 3. ed. Thousand Oaks, CA: Sage Publications, 2003. 